\begin{tabular}{|c|c|}
\hline Title & In-situ Raman Spectroscopy for the Passive Oxide Film on Iron in Neutral Borate Solution \\
\hline Author(s) & Ohtsuka, Toshiaki; Taneda, Kento \\
\hline Citation & $\begin{array}{l}\text { ECS Transactions, 16(52), 125-131 } \\
\text { https://doi.org/10.1149/1.3229961 }\end{array}$ \\
\hline Issue Date & 2009 \\
\hline Doc URL & http:/hdl.handle.net/2115/60230 \\
\hline Rights & $\begin{array}{l}\text { () The Electrochemical Society, Inc. 2009. All rights reserved. Except as provided under U.S. copyright law, this work } \\
\text { may not be reproduced, resold, distributed, or modified without the express permission of The Electrochemical Society } \\
\text { (ECS). The archival version of this work was published in ECS Transactions, V olume 16, Issue 52, pp. 125-131, } 2009 .\end{array}$ \\
\hline Type & article \\
\hline File Information & OhtsukaECS16(52-125).pdf \\
\hline
\end{tabular}

Instructions for use 


\title{
in-situ Raman Spectroscopy for the Passive Oxide Film on Iron in Neutral Borate Solution
}

\author{
Toshiaki Ohtsuka and Kento Taneda
}

\begin{abstract}
Graduate School of Engineering, Hokkaido University, Kita 13 Nishi 8, Kita-ku, Sapporo 060-8628 Japan
\end{abstract}

\begin{abstract}
In-situ Raman spectra of the passive oxide film in neutral borate solution at $\mathrm{pH} 8.4$ was measured without any enhancement such as surface enhanced Raman scattering or resonance Raman scattering. To measure the Raman spectra of the surface thin film on the electrode, we introduced a confocal collection system to reject the scattering signal from the electrolytes surrounding the surface in front of the spectrometer. The background signal is still high, and it is more intensive by 100 times than the Raman signal from the passive film. The difference Raman signal between the surfaces of the passivated iron and the reduced bare iron reveals a peak at about $670 \mathrm{~cm}^{-1}$. When we measured the passivated iron surface soon after transfer from the electrolytes to air, we observed another broad and faint peak at $320 \mathrm{~cm}^{-1}$. From these peaks, we assume that the passive oxide film on iron is composed of $\mathrm{Fe}_{3} \mathrm{O}_{4}$ and $\gamma$ $\mathrm{Fe}_{2} \mathrm{O}_{3}$.
\end{abstract}

\section{Introduction}

The composition of passive oxide film has been for the subject of discussion for a long time by various authors. The film has been examined by various in-situ and ex-situ techniques. The ex-situ techniques such as XPS ${ }^{(1)}$, AES $^{(2)}$, SIMS $^{(3)}$ and the like are very sensitive to surfaces in vacuum condition; however, the environmental change from aqueous medium to vacuum condition may induce an unpredictable change in oxide film. In-situ detection of the film is, therefore, desirable, but the detection is very restricted by the sensitivity of the techniques applied due to the extremely small thickness of the film and the undesirable background signal from the surrounding aqueous medium.

Under the in-situ condition, O'Grady ${ }^{(4)}$ and Berett et al. ${ }^{(5)}$ applied Mossbauer spectroscopy to the passive oxide film on iron and proposed a hydrated Fe(III) oxyhydroxide with a polymeric structure containing $\mathrm{OH}$ bridges. Kruger et al. ${ }^{(6)}$ and Dabenport et al. ${ }^{(7)}$ applied $X$ ray absorption with a suitable design for the cell and electrode arrangement. Raman spectroscopy is also one of the candidates to detect passive film in-situ. To detect thin passive film, surface enhanced Raman scattering (SERS) was applied, in which fine silver particles were cathodically deposited on the iron surface before the anodic passivation or the thin iron film covered the roughening silver surface . ${ }^{(8-13)}$ When one applies to the electrode the potential high enough to realize passivation, the silver particles or substrate are oxidized and the electrode loses the property of the Raman enhancement. The potential range for the SERS detection, therefore, results in restriction in the low potential region from the active to the initial passive region. Further, the deposition of the silver particles on the surface may have an unexpected influence on passive oxide film. Although normal Raman scattering can 
detect thin oxide film a few nanometers thick in vacuum, in the aqueous media the Raman scattering signal from the surface thin oxide film was difficult to distinguish from the scattering light from the surrounding aqueous medium.

In this study we applied normal Raman scattering to the passive oxide film on iron in neutral borate solution at $\mathrm{pH} 8.4$ with a confocal collection system of the scattering light to reject the scattering light from the surrounding aqueous solution.

\section{Experimental}

The iron electrode used was a rod with $5 \mathrm{~mm}$ diameter and $99.99 \%$ purity, purchased from Johnson-Matthey Chemicals. The cross-section of the iron rod was polished to a mirror-like surface by alumina abrasive of $0.05 \mathrm{~mm}$ diameter and used as the electrode.

Raman scattering spectra were measured by a spectrometer of $300 \mathrm{~mm}$ optical path equipped with a cut-edge filter for the removal of Rayleigh scattering and diffuse reflected lights and with a CCD camera, Andor DU401A, to capture spectrograms. For collection of the Raman scattering light from the electrode, we adopted the confocal optical system shown in Fig. 1. The system consisted of four lenses and a pin-hole with $50 \mu \mathrm{m}$ diameter. The first lens, with $10 \mathrm{~mm}$ focus length (Mitsutoyo, G-Plan-Apo-20), was specially designed to be optimized for collection of the scattering light from the electrode surface through a $3 \mathrm{~mm}$ water layer and a $0.5 \mathrm{~mm}$ thick quartz glass window. The pin-hole, which was located at the focal point of the second lens, could efficiently reject the scattering light from electrolytes surrounding the electrode surface.

The Raman measurement of the electrode surface was made with excitation of the Ar ion laser beam line of $514.5 \mathrm{~nm}$ wavelength at $100 \mathrm{~mW}$ output power, and the Raman scattering light was accumulated with $10 \mathrm{~s}$ exposure time and 100 repetitions.

The optical-electrochemical cell was made of a polychlorotrifluoroethylene rod with $100 \mathrm{~mm}$ diameter. An area $50 \mathrm{~mm}$ long by $60 \mathrm{~mm}$ in diameter was drilled in the rod from a side wallThe drilled area on the side wall was covered by an optical flat quartz glass with $0.5 \mathrm{~mm}$ thickness. The rod electrode was inserted from the back side into the cell part through a hole with two sealing O-rings. The electrode surface was fixed at a position $3 \mathrm{~mm}$ from the glass window. The measurement was made at room temperature of $25^{\circ} \mathrm{C}$.

The electrolytes were in a borate buffer solution at $\mathrm{pH} 8.4$, which was a 1:1 mixture of $0.3 \mathrm{~mol} \mathrm{dm}^{-3}(\mathrm{M}) \mathrm{H}_{3} \mathrm{BO}_{3}$ and $0.075 \mathrm{M} \mathrm{Na}_{2} \mathrm{~B}_{4} \mathrm{O}_{7}$ aqueous solutions. The electrolyte solution was prepared from milli-Q water and analytical grade agents.

\section{Reaults and Discussion}

The Raman scattering lights were separately measured with $1000 \mathrm{~s}$ accumulation time $(=(10 \mathrm{~s}$ exposure $)(100$ repeated times $))$ for the surface reduced by constant current at 10 $\mu \mathrm{A} \mathrm{cm} \mathrm{cm}^{-2}$ for $1200 \mathrm{~s}$ and for the surface passivated by constant potential in the anodic region for $3600 \mathrm{~s}$, and the spectrogram measured for the reduced surface was subtracted from those for the passivated surfaces. Figure 2 shows the Raman spectra scattered from a reduced and passivated surface at $0.7 \mathrm{~V}$ vs. $\mathrm{Ag} / \mathrm{AgCl} /$ saturated $\mathrm{KCl}$. It may be impossible to distinguish the difference between them. The four peaks on the wide background in Fig. 2 correspond to the Raman peaks from the borate ions in the electrolyte solution.

Figure 3 indicates the difference spectra, in which the Raman scattering spectra from the iron reduced at the constant current are subtracted from those from the iron passivated 
at various potentials. While the original spectrograms had a background signal with about 10-20 counts per second (cps), the subtracted spectra indicate vary small peaks in the $0.01 \mathrm{cps}$ order. An intense Raman peak at $875 \mathrm{~cm}^{-1}$ was observed, which corresponded to the strongest Raman peak of borate ions in Fig. 2. In addition to the Raman peak of borate anions, the difference spectra in Fig. 3 exhibit a small and broad peak at about 670 $\mathrm{cm}^{-1}$, and the peak intensity increases as potentials increase from $0.02 \mathrm{cps}$ to $0.04 \mathrm{cps}$. Another faint peak is observed at $320 \mathrm{~cm}^{-1}$ and also increases with potential.

When we measured the passivated surface under ex-situ condition in air soon after removal of the electrode from the electrolyte solution, we observed clearer Raman peaks, which are given in Fig. 4. In Fig. 4, the background signal is not appreciable and the Raman peak at $670 \mathrm{~cm}^{-1}$ is clearly distinguishable. In addition, a small peak at about 320 $\mathrm{cm}^{-1}$ can be observed. The ex-situ spectrum is almost the same as that previously reported. (14)

\section{Discussion}

The difference spectra measured under the in-situ condition reveal two peaks at 670 and $320 \mathrm{~cm}^{-1}$ whose intensities range from 0.01 to $0.04 \mathrm{cps}$. The background signal in the original spectrum is $10-20 \mathrm{cps}$, which is $10^{3}$ times more intense than the Raman signal of the passive oxide film. If one measures the Raman spectra without the confocal optical system applied in this study, the stronger background signal from the electrolyte solution hinders the Raman observation of the passive oxide film. The system used in this study greatly weakens the background Raman signal.

The in-situ spectrum is not largely different from the ex-situ spectra, except for the large background signal from the electrolyte solution in the in-situ spectra. This means that the change that occurs in the passive film when it is transferred from the electrolyte solution to air is not fast enough to be distinguishable within a few hours.

The Raman spectra were compared with the reference spectra of various iron oxides and oxyhydroxides, which were previously reported by us.

Although the spectra measured are broad and do not exhibit clear peaks, the passive oxide may basically be considered an amorphous-like Fe(III) oxide and oxyhydroxide. In the Raman spectra of iron oxides and oxyhydroxides, $\mathrm{Fe}_{3} \mathrm{O}_{4}, \gamma-\mathrm{Fe}_{2} \mathrm{O}_{3}$, and $\delta$ - $\mathrm{FeOOH}$ possess the strongest peak at a Raman shift of about $600-700 \mathrm{~cm}^{-1}$ in the individual Raman peaks; for example, the strongest peak of $\mathrm{Fe}_{3} \mathrm{O}_{4}$ is $670 \mathrm{~cm}^{-1}, \gamma-\mathrm{Fe}_{2} \mathrm{O}_{3}$ is $680 \mathrm{~cm}^{-1}$, and $\delta$-FeOOH is $700 \mathrm{~cm}^{-1 .(11,13,14,17,18)}$ From the second peak at $300-400 \mathrm{~cm}^{-1}$ observed under the ex-situ condition as well as the in-situ condition, one can select the compounds of $\mathrm{Fe}_{3} \mathrm{O}_{4}$ and $\gamma-\mathrm{Fe}_{2} \mathrm{O}_{3}$ as candidates for the passive oxide. The assignment is in agreement with the presumption derived by Graham et al., from the results by SIMS and XPS. They assumed that the passive oxide film was composed of $\mathrm{Fe}_{3} \mathrm{O}_{4}$ at the oxide/metal interface and $\gamma-\mathrm{Fe}_{2} \mathrm{O}_{3}$ at the oxide/solution interface. Our results support this estimation. The spectra in this work indicate that the passive film is not largely hydrated, although the oxide is formed in the aqueous solution. Ohtsuka et al. discussed the dehydration of the hydrated oxide film induced by a high electric field crossing the passive oxide film on iron as well as nickel ${ }^{(15)}$ and titanium ${ }^{(16)}$. The hydration-dehydration change will be examined further.

For the passivation surface, the in-situ SERS (surface enhanced Raman scattering) technique has been applied to identify the composition of the passive oxide formed in neutral and slightly alkaline solutions. ${ }^{(8-12)}$ For the SERS, silver particles were deposited on the iron surface before the passive film formation or the silver surface roughened by 
the electrochemical oxidation-reduction cycles was covered by the iron deposit which was then passivated. In these SERS studies, a large peak at about $550-600 \mathrm{~cm}^{-1}$ was reported and assumed to be a Raman peak of the passive oxide. The peak started to be observed in the relatively low potential corresponding to the active to the transient region and continued to the passive potential region. For the SERS measurement, the potential is restricted in the initial of passivation, because the silver causing the enhancement of Raman scattering is oxidized to silver oxide and thus loses the enhancement effect. Among iron oxides, oxyhydroxides, and hydroxides, only $\mathrm{Fe}(\mathrm{OH})_{2}$ exhibits a main Raman peak at about $500-600 \mathrm{~cm}^{-1}$. ${ }^{(13)}$

We found no evidence of $\mathrm{Fe}(\mathrm{OH})_{2}$ in the passive potential region from the viewpoint of thermodynamic study or the many earlier results on the passivation. We believe that the Raman scattering of $\mathrm{Fe}^{2+}$ ions, $\mathrm{Fe}(\mathrm{OH})_{2}$ or its oxidized hydrated compound, is enhanced by the effects of the silver particles or substrates in the active, passive, and initially passive potential regions. In a previous paper, we reported that $\mathrm{Fe}^{2+}$ ions in electrolyte solution are deposited on the passive oxide film as an outer hydrated layer and can grow to much thicker than the passive film. ${ }^{(19,20)}$ When one polarizes the iron electrode potential in the active region, $\mathrm{Fe}^{2+}$ dissolves into the electrolyte solution at neutral $\mathrm{pH}$. Then, when one changes the potential in the passive region, in addition to the thin passive oxide film, the thick outer hydrated layer can be formed by the anodic deposition from $\mathrm{Fe}^{2+}$ that was dissolved into the electrolyte solution at the previous active potential. We assume that the Raman peak at $550-600 \mathrm{~cm}^{-1}$ observed by the SERS studies does not correspond to that of the passive oxide film, but to a hydrate layer deposited from $\mathrm{Fe}^{2+}$ in the electrolyte solution.

\section{Conclusion}

In-situ Raman spectra of the passive oxide film on iron in neutral borate solution is successfully measured by a Raman apparatus equipped with a confocal optical system to reject the strong background signal from the electrolytes surrounding the electrode surface. The Raman peaks at $670 \mathrm{~cm}^{-1}$ and $320 \mathrm{~cm}^{-1}$ are assigned to those of the passive oxide film. Those peaks indicate that the passive oxide film is composed of $\mathrm{Fe}_{3} \mathrm{O}_{4}$ and $\gamma$ $\mathrm{Fe}_{2} \mathrm{O}_{3}$.

\section{Acknowledgement}

This work was financially supported by New Energy and Industrial Technology Development Organization, Japan, Project No. 06990866.

\section{References}

(1) T. Konno and M. Nagayama, Passivity of Metals, R. P. Frankelthal and J. Kruger, Editors, p. 585, The Electrochemical Soc., Inc., Princeton, NJ (1978) .

(2) M. Seo, J. B. Lumsden, and R. W. Steel, Corrosion Sci., 50, 541 (1975).

(3) D. F. Mitchell and M. J. Graham, J. Electrochem. Soc., 133, 936 (1986).

(4) W. E. O'Grady, J. Electrochem. Soc., 127, 555 (1980).

(5) M. E. Brett, K. M. Parkin, and M. J. Graham, J. Electrochem. Soc., 133, 2031 (1986).

(6) J. Kruger, Corrosion Sci., 29, 149 (1989).

(7) A. J. Davenport, J. A., Bardwell, H. S. Isaacs, and B. MacDougall, Modification of Passive Films, P. Maucus, B. Bauoux, and M. Keddam, Editors, p. 57, The Institute 
of Materials, London (1994).

(8) J. C. Rubim and J. Dunnwald, J. Electroanal. Chem., 258, 327 (1989).

(9) J. Gui and T. M. Devine, Corrosion Sci., 32, 1105 (1991).

(10) J. Gui and T. M. Devine, Corrosion Sci., 36, 441(1994).

(11) J. Gui and T. M. Devine, Corrosion Sci., 37, 1177 (1995).

(12) L. J. Oblonsky, S. Virtanen, V. Schroeder, and T. M. Devine, J. Electrochem. Sco., 144, 1604 (1997).

(13) N. Boucherit, A. Hugot-Le Goff, and S. Joiret, Corrosion Sci., 32, 497 (1991).

(14) T. Ohtsuka, Materials Transaction Japan Inst. Metals, 37, 67 (1996).

(15) T. Ohtsuka and S. Iida, Corrosion Sci., 49, 1408 (2007).

(16) T. Ohtsuka and N. Nomura, Corrosion Sci., 39, 1253 (1997).

(17) T. Ohtsuka, K. Kubo, and N. Sato, Corrosion, 42, 476 (1986).

(18) R. J. Thibeau, C. W. Brown, and R. H. Heidersbach, Appl. Spectrosc., 32, 532 (1978).

(19) T. Ohtsuka, J.-C.Ju, S.Ito, and H.Einaga, Corrosion Sci., 36, 1257 (1994).

(20) T. Ohtsuka and H. Yamada, Corrosion Sci., 40, 1131 (1998). 


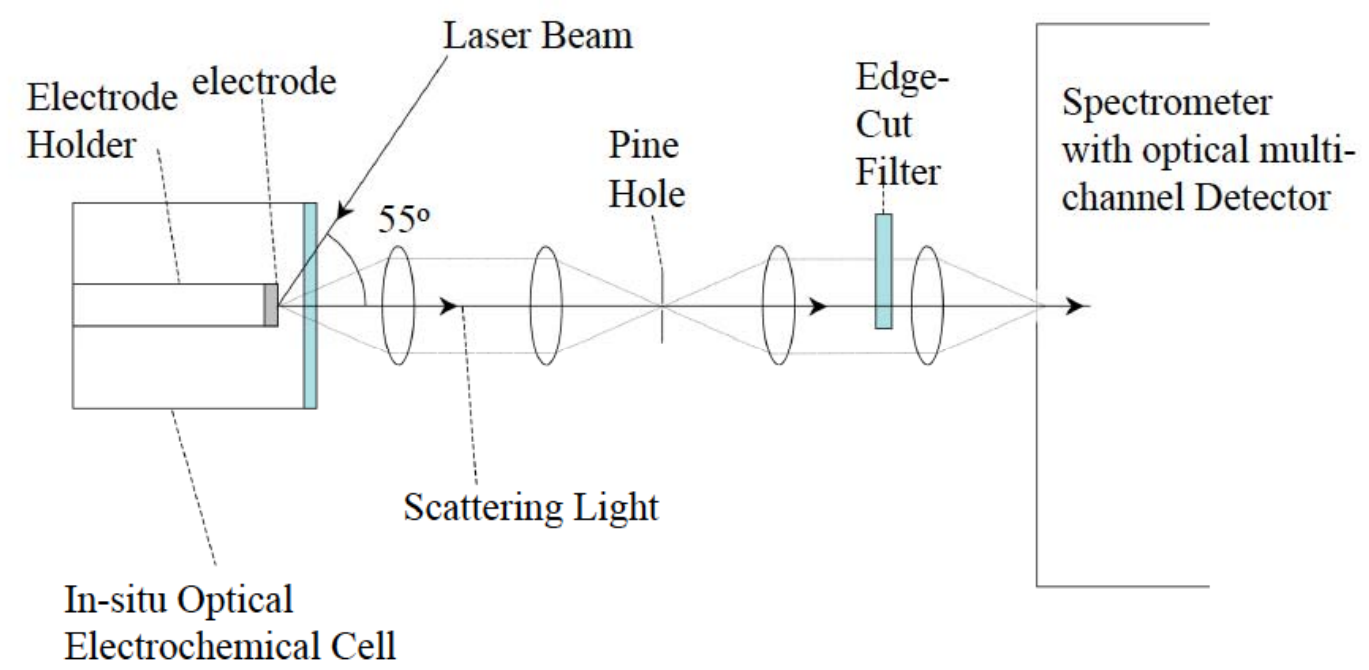

Fig. 1 Confocal optical system to reject the scattering light from the electrolytes surrounding the electrode surface.

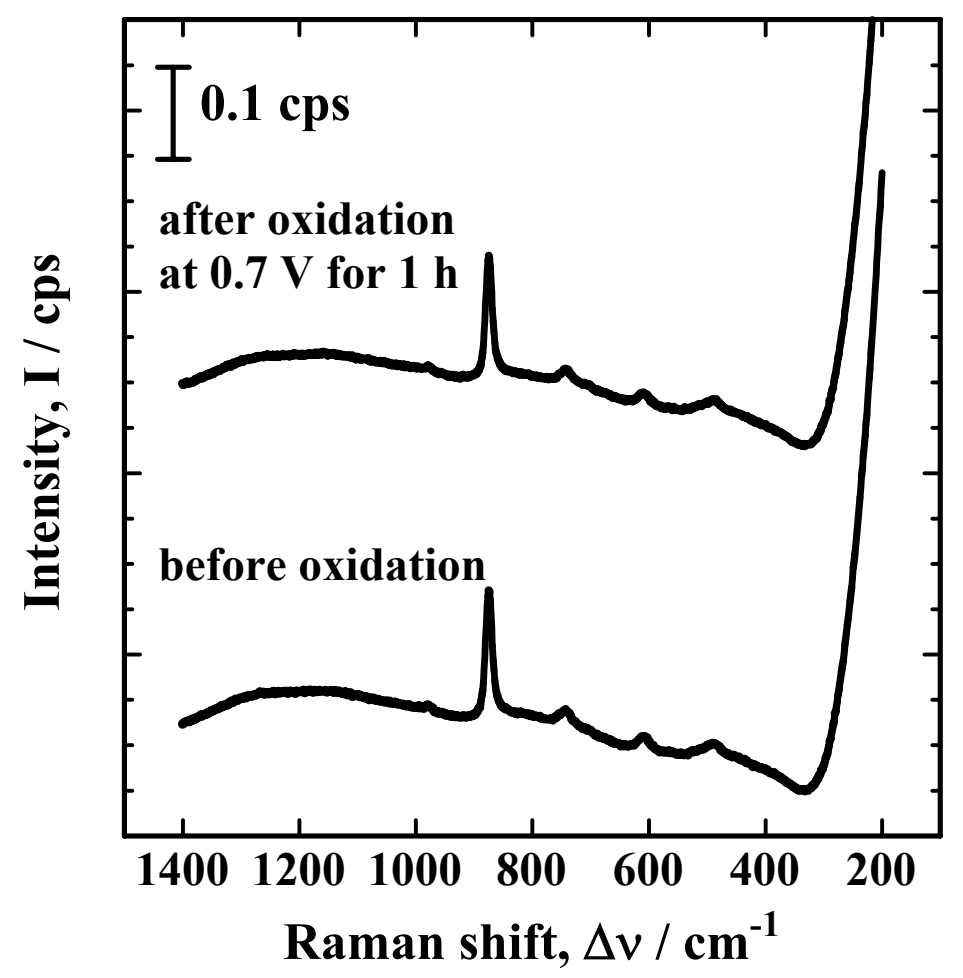

Fig. 2 Raman spectra from the iron electrode reduced at a constant current of $10 \mu \mathrm{A} \mathrm{cm}{ }^{-2}$ and oxidized at $0.7 \mathrm{~V}$ vs. $\mathrm{Ag} / \mathrm{AgCl} /$ saturated $\mathrm{KCl}$ in the neutral borate solution at $\mathrm{pH} 8.4$. 


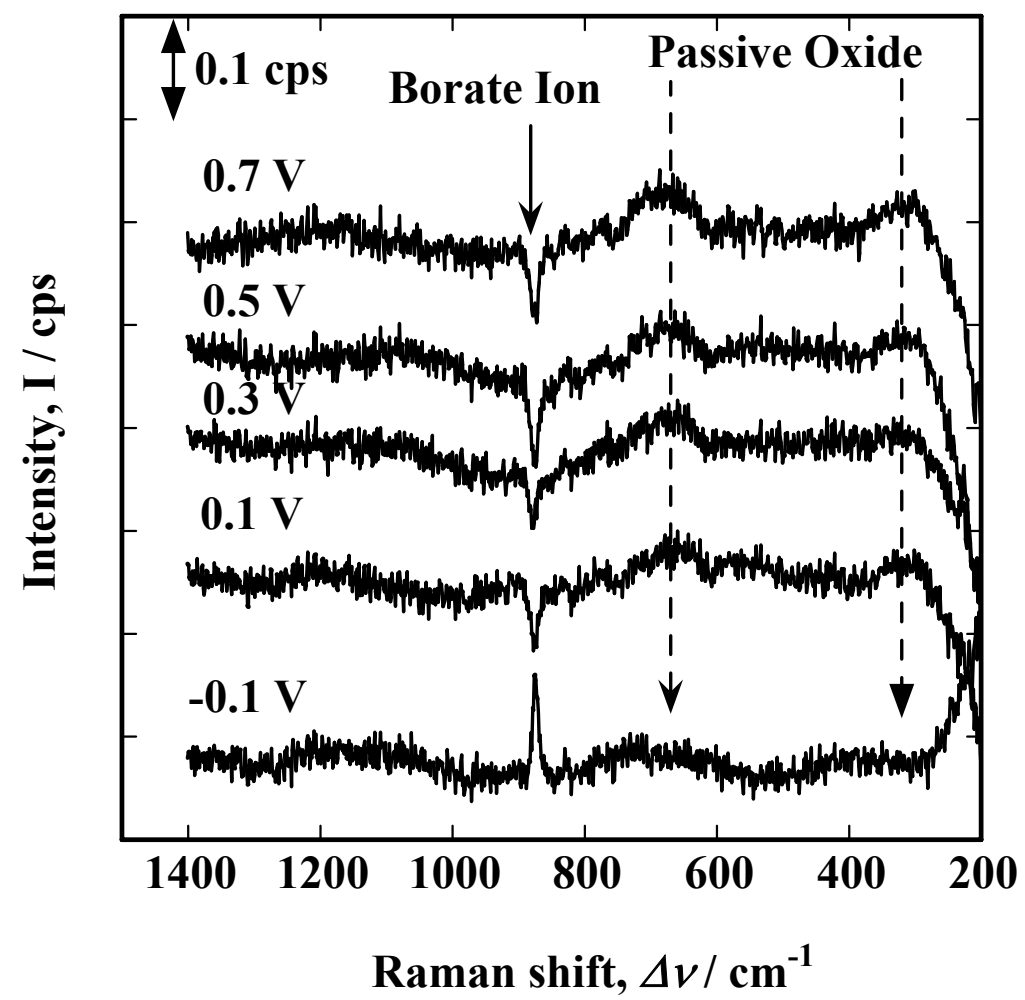

Fig. 3 Difference Raman spectra of the passivated iron electrode in the neutral borate solution at $\mathrm{pH} 8.4$ under the in-situ condition. The spectra are derived by the subtraction from the spectra of the ion passivated to the spectrum of the iron reduced.

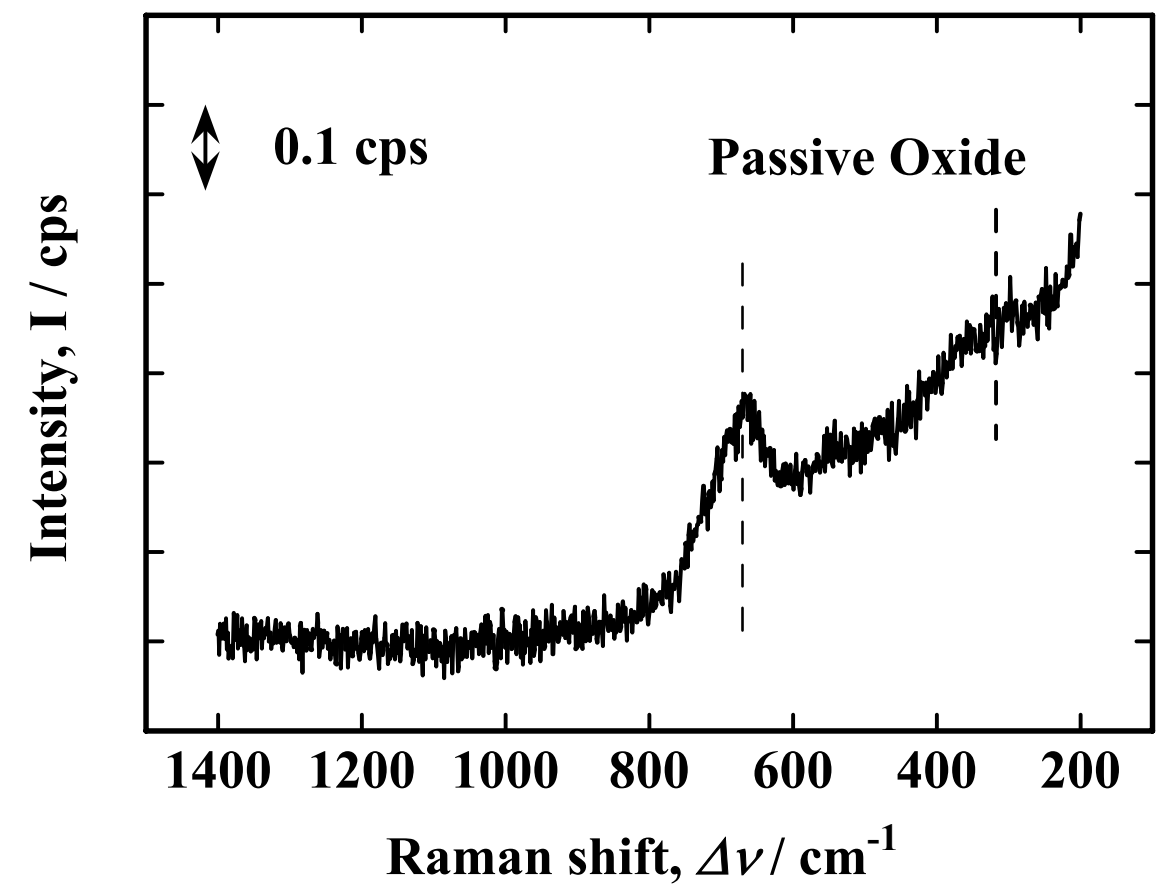

Fig. 4 Raman spectrum of the iron passivated at $0.7 \mathrm{~V}$ under the ex-situ condition in air. The iron was first passivated at $0.7 \mathrm{~V}$ in the neutral borate solution at $\mathrm{pH} 8.4$, and then the Raman spectra were measured immediately after removal from the electrolyte solution. 